\title{
Subjetividades del Profesorado de Artes y su Rol como Agentes/as de Cambio
}

\author{
Subjectivities of the Arts Teachers and its Role as Agents of \\ Change
}

\author{
Rosario García-Huidobro * \\ Ninoska Schenffeldt Ulloa \\ Universidad de Los Lagos, Chile
}

\begin{abstract}
Se muestran los resultados del estudio "Identidades profesionales de los/as artistasdocentes en la Región de Los Lagos. Transformaciones de lo social en compromiso cultural”, que buscó conocer las subjetividades del profesorado de artes visuales de la Región de Los Lagos en Chile y comprender cómo dichas subjetividades contribuyen hacia el desarrollo social y cultural de la región. Se utilizó una metodología mixta; con la aplicación de una encuesta y cuatro grupos focales. Como principales resultados de la fase cualitativa, encontramos que la conformación de subjetividades de los/as artistas-docentes y su aporte social y cultural surge a partir de tres categorías: i) Creación Artística Personal Situada; su hacer es una práctica situada que conlleva decisiones políticas del cómo repensar el mundo en un contexto dado, por lo que es ontológico-episte-metodológico. ii) Lo Artístico; que transformará y mediará en el espacio social y iii) Agentes de cambio; donde saca del aula la acción transformadora, promoviendo la acción participativa más allá de lo formal. Estas prácticas onto-episte-metodológicas de los/as artistas-docentes son acciones que van directamente a disrumpir el espacio artístico-social previamente establecido. Las subjetividades del/la artista docente es la posibilidad misma de transformación social del territorio, generando nuevos sentidos, como una forma colaborativa de promover cambios a través de las artes.
\end{abstract}

Descriptores: Subjetividad; Artista; Docente; Comunidad; Cambio social.

The article shows the results of the study "Professional subjectivities of artiststeachers in the Los Lagos Region. Transformations of the social into cultural commitment", which sought to know the subjectivities of the visual arts teachers of the Region Los Lagos in Chile and understand how these subjectivities contribute to the social and cultural development of the region. A mixed methodology was used, with the application of one survey and four focus groups. As main results of the qualitative phase, we find that the shaping of the subjectivities of the artists-teachers and their social and cultural contribution arises from three categories: i) Personal Artistic Creation Located; its doing is a situated practice that involves political decisions of how to rethink the world in a given context, making it ontologicalepiste-methodological. ii) The Artistic; which will transform and mediate in the social space and iii) Agents of change; where it takes transformative action out of the classroom, promoting participatory action beyond the formal. These onto-epistemethodological practices of the artists-teachers are actions that go directly to disrupt the previously established social-artistic space. The subjectivities of the teaching artist are the very possibility of social transformation of the territory, generating new senses, as a collaborative way of promoting changes through the arts.

Keywords: Subjectivity; Artist; Teacher; Community; Social change.

*Contacto: rosario.garcia-huidobro@ulagos.cl

ISSN: 2254-3139

www.rinace.net/riejs/

revistas.uam.es/riejs
Recibido:

$1^{\text {a }}$ Evaluación:

$2^{\text {a Evaluación: }}$

Aceptado:
15 de marzo 2020

25 de mayo 2020

9 de agosto 2020

29 de septiembre 2020 


\section{Introducción}

El presente artículo muestra los resultados cualitativos del estudio "Identidades profesionales de los/as artistas-docentes en la Región de Los Lagos. Transformaciones de lo social en compromiso cultural", que se ha realizado en el sur de Chile ${ }^{1}$. Este proyecto surgió del interés por las experiencias del profesorado de artes visuales en Chile y de la pregunta por ¿cómo conforman sus identidades y subjetividades en tanto profesionales de la enseñanza artística y de qué manera su compromiso social se refleja en el desarrollo cultural de la región? Estas preguntas surgen tras la falta de estudios nacionales que trasciendan la caracterización del área de la educación artística en Chile (Cobos, 2013; Errázuriz et al., 2014; Llona, 2011) y que puedan revalorizar el rol de las artes en los contextos sociales y educativos desde la voz de quienes la encarnan.

En 2011, se desarrolló el Estudio sobre el Estado Actual de la Educación Artística en la Región Metropolitana, a cargo del Instituto para el Desarrollo y la Innovación Educativa (IDIE), liderado por Eugenio Llona. Tanto este estudio, como el desarrollado por el Consejo de la Educación Artística y Cultura en Chile (2012), se expresa que una de las debilidades de la enseñanza artística chilena es que dicho profesorado no tiene la especialidad artística requerida y que, por ende, esta disciplina era implementada en gran medida por profesionales de la educación que no poseían la formación ideal para esta labor (Eugenio Llona, 2011). Además, se señala que el 51\% del profesorado de artes (que en la realidad chilena obedece a un porcentaje alto de educación básica, educadoras de párvulos, psicopedagogas/os y otros docentes), si bien posee herramientas pedagógicas y metodológicas, lamentablemente no comprendían o dominaban con profundidad los contenidos específicos, el lenguaje artístico apropiado, las técnicas artísticas y los recursos necesarios para enseñar artes visuales. Frente aquella debilidad, sostienen que solo el 34\% del profesorado que enseña artes son profesionales preparados para esta labor, puesto "que tienen formación pedagógica y también poseen los conocimientos y habilidades propios del oficio del artista" (Llona, 2011, p. 45). Nos parecen preocupantes dichos resultados y afirmaciones, puesto que el estudio no observa ni analiza el rol social de las artes y del profesorado, en contextos donde la educación artística es marginada y vulnerada. A partir de aquí nos parece necesario valorar el quehacer artístico docente y poner atención a cómo dicho ejercicio trasciende el manejo de técnicas y contenidos y se conecta con los elementos culturales y sociales en donde se sitúan las escuelas.

En Chile se puede observar el paso del arte por el arte (una instancia propositiva) hacia una visión de la educación artística que impacta socialmente y que apunta a la creatividad social (Ossa, 2017). No realizaremos esta valorización a modo de genealogía, tampoco se explicarán las distintas perspectivas de la educación artística (Aguirre, 2005; Carrasco y García-Huidobro, 2016; Raquimán y Zamorano, 2017), y la escasa apropiación que han tenido para formular un pensamiento propio en Latinoamérica y que tome lo social como un aspecto relevante e identitario en el área de las artes y la educación chilena. Sin embargo, nos parecen relevantes las aportaciones que Carlos Ossa (2017) ha entregado a la educación artística en Chile, al complejizar la discusión sobre las dificultades de esta área de enseñanza y las perspectivas artísticas planteadas por Imanol Aguirre (2005) y

\footnotetext{
${ }^{1}$ Realizado a través de los fondos del Concurso Regular Interno de la Universidad de Los Lagos, entre 2018-2020.
} 
preguntarnos “ ¿qué modelos de investigación en Educación Artística y creatividad social pueden contribuir a un replanteamiento epistemológico de la enseñanza, tanto en su nivel formal como no formal?” (Ossa, 2017, p. 9). Esta pregunta nos parece clave para valorizar la educación artística chilena, y ver en lo propio, elementos que son un aporte para el desarrollo de nuestro país.

A partir de aquí, el objetivo principal de la investigación ya concluida fue conocer las subjetividades del profesorado de artes visuales de la región de Los Lagos en Chile y comprender cómo la conformación de sus subjetividades y su acción artística pedagógica contribuye hacia el desarrollo social y cultural de la región.

A su vez nos propusimos cuatro objetivos más específicos, sin embargo, en esta fase del estudio se exploraron los dos últimos: (3) Cómo el profesorado de artes vincula sus proyectos artísticos-educativos con las necesidades del entorno y, por último, (4) Describir las características que componen las prácticas docentes y artísticas de dichos docentes y analizar cómo impactan en el desarrollo social y cultural de la región.

En el presente artículo abordaremos las prácticas docentes desde los procesos artísticos encarnados en la escuela, donde lo personal, profesional y político están relacionados no solo en su proximidad con el aula, sino que conforman un sentido amplio que promueve el agenciamiento para las transformaciones sociales de lo que significa enseñar artes en un contexto que margina y no da crédito a la asignatura en las escuelas (Carrasco y GarcíaHuidobro, 2016).

En los siguientes apartados se describe la metodología y el método de acercamiento al profesorado de artes visuales en la región de Los Lagos para conocer sus experiencias. Posteriormente se plantea una discusión teórica sobre la noción de subjetividad docente y, a partir de la aportación del pensamiento postestructuralista y de los Nuevos Materialismos se explica el acercamiento a la subjetividad de artistas-docentes. Luego se explican las categorías emergentes que se identificaron tras el análisis y se profundizan los conceptos más relevantes junto al relato de algunos/as participantes. A partir de estos elementos, el estudio permitió conocer las identidades artísticas y docentes de quienes habitan el territorio sur austral y que surgen desde lo imbricado e interrelacionado en un entorno territorial-local (artístico, cultural, pedagógico, etc.) que está rodeado de elementos materiales que les permiten desarrollarse, pensarse y accionarse como tales.

\section{Subjetividades del profesorado de artes}

La subjetividad docente ha sido explorada desde diversas perspectivas, ha tenido una trayectoria y rol significativo en la investigación educativa, por cuanto ha permitido situar nuevos elementos que afectan sus sentidos de ser y hacer en educación. Dentro de los estudios sobre la subjetividad docente, encontramos algunos más vinculados al construccionismo social y que ponen foco en sus construcciones personales con las trayectorias profesionales y las condiciones escolares (Cornejo, 2008, 2009; Sancho y Hernández, 2014; Theobald, 1990; Vezub, 2007; Wittrock, 1986, entre otros). Otros estudios sobre la subjetividad docente ponen mayor foco en aspectos biográficos desde la perspectiva narrativa (Day, 2006; Goodson, 2004; Ríos, 2018; Rivas y Herrera, 2009) y otros se preguntan por la subjetividad en relación a la construcción del saber docente (García-Huidobro, 2019; Mercado, 1991; Salguero, 1998; Tardif, 2004). Por último, encontramos algunos estudios que, al situarse en perspectivas postestructuralistas y de 
los Nuevos Materialismos, exploran formas de concebir los procesos de subjetividad docente con un foco en lo situado, donde la corporeidad, las relaciones y los afectos son elementos relevantes para apropiarse de los procesos de subjetividad (Arévalo e Hidalgo, 2015; Carrasco y Hernández, 2020; Montenegro 2019).

El cruce y aportes de estos estudios nos han permitido situar a la dimensión de la subjetividad del profesorado, en la presente investigación, como un espacio de ser y hacer interdisciplinario y en constante conformación. Tras esto, visualizamos a la subjetividad docente como un desplazamiento de experiencias que no son lineales.

En el caso de este estudio, al estar enfocados en experiencias de artistas-docentes, nos parece relevante subrayar la capacidad de ser artista y docente en acción, como un elemento relevante en los procesos de subjetividad que van más allá de lo discursivo. Esto abre a la subjetividad como una construcción continua que surge desde el posicionamiento en un tramado rizomático de las múltiples formas de estar en un contexto artístico y educativo; lo que entendemos como posiciones intersubjetivas. Rosi Braidotti (1991) explica que la subjetividad es una multiplicidad de posiciones y "el sujeto es un proceso hecho de desplazamientos, negociaciones constantes entre niveles diferentes de poder" (p. 99). Desde aquí pensaremos en la subjetividad del profesorado de artes como un desplazamiento constante entre lo artístico y lo pedagógico, lo que Hall (2010) ha expresado como híbrido y, por ende, con un sentido onto-epistemológico que está en constante relación de movimiento (García-Huidobro 2018; Viveros, 2020). En el proceso de ir siendo artista-docente en la escuela se va construyendo una relación dialógica entre el hacer artístico y pedagógico. Por ello, si un/a artista-docente pierde ese diálogo, esa capacidad de decidir y de transitar entre ambas realidades, deja de ser sujeto activo en esa relación y, por ende, se dejan de producir sentidos intersubjetivos entre las artes y la enseñanza. Los sentidos subjetivos del profesorado de artes, más que ser producciones discursivas, se centran en un ser y hacer; una acción artística y docente que se da en un proceso continuo, situado, onto-epistemológico y que se expresa en sus relaciones con el mundo. Estas relaciones de estar en el mundo se materializan y corporeizan en un contexto situado, el que tendrá distintas repercusiones y aportaciones según el contexto.

\section{Subjetividades situadas y la onto-episte-metodología de los/as artistas-docentes}

El acercamiento epistemológico que desarrolló Sandra Harding (1987, 1993), desde un posicionamiento de investigación feminista standpoint, fue el punto de partida para argumentar que la experiencia situada es la base de todo conocimiento. A partir de ello, la perspectiva feminista ha propuesto modos alternativos de conocimiento, que legitimen a los/as sujetos como agentes de saber. Es decir, que valoren su saber cómo un conocimiento que ha sido opacado por la hegemonía patriarcal y que surge desde la subjetividad y conocimiento situado, como posibilidades materiales y relacionales de ir siendo (Alcoff y Potter, 1993). Estas ideas nos han enseñado que las producciones y pensamientos que encarnan los/as sujetos no son neutros, sino que situados, ya que emergen desde una localización singular y subjetiva que transforma a dichas acciones e ideas en saberes de la experiencia y en su propio devenir (García-Huidobro, 2019).

En relación a estas ideas, lo situado es un elemento inherente de la subjetividad. De hecho, diremos que la subjetividad es, justamente, los tránsitos y recorridos de nuestros posicionamientos. No es posible comprender los procesos intersubjetivos si no observamos o damos cuenta sobre cómo los/as sujetos viven y transitan entre sus situaciones y contextos. 
Con estos antecedentes nos parece relevante comprender la relación que existe entre lo situacional, es decir, el dónde está situado el profesorado de las artes, sus conocimientos, experiencias artísticas y docentes y cómo todo ello nos lleva a comprender la construcción de dichas subjetividades. Respecto al dónde se sitúan los/as artistas docentes de este estudio, se plantean dos puntos de inicio que son relevantes y que no podemos obviar al acercarnos a conocer sus formas de subjetividad.

La primera es observar el lugar de localización geográfica en donde se desarrolla este profesorado y las implicancias que significa ser artista-docente en esa localidad y situación. En el caso de esta investigación, la población con la cual se desarrolló esta segunda fase son artistas-docentes que pertenecen a la Región de Los Lagos, en el sur de Chile, un contexto con escasa oferta artística y cultural y donde las escuelas dejan al margen a la educación artística (Carrasco y García-Huidobro, 2016).

Para contextualizar esta realidad regional, según el Informe Anual de 2018 sobre estadísticas culturales que entregó el Instituto Nacional de Estadísticas en Chile (INE, 2018), la Región de Los Lagos solo recibe un 4,7\% del Fondo Nacional de Desarrollo Cultural y Las Artes de proyectos regionales. Asimismo, la distribución de los Fondos de Arte y Cultura Nacional son de un 2,0\% para la Región de Los Lagos, mientras que para la Región Metropolitana es de un 60,7\%. Por otro lado, según el Informe de Políticas Culturales de la Región de los Lagos 2017-2022, del Consejo Nacional de la Cultura y las Artes (2017), en la región se desarrollan actividades artísticas que son centralizadas, realizándose en mayor medida en las comunas de Puerto Montt y Osorno, dejando a otras veintiocho comunas de la región relegadas de espacios y actividades culturales. A esto se suma que el promedio de asistencia a eventos culturales como conciertos, "exposiciones de artes visuales, museos, cine, juegos tradicionales y populares, biblioteca y proyectos de arte y tecnología, está por debajo del promedio de asistencia del promedio nacional" (Consejo Nacional de la Cultura y las Artes, 2017, p. 37). Dado el contexto de vulnerabilidad para el área artística y que afecta a la enseñanza de las artes en esta la región, nos parece que los/as artistas-docentes se sitúan en un escenario complejo y desafiante, donde su hacer pedagógico como promotores de las artes y la cultura es clave.

Respecto a la segunda forma de entender lo situacional de los/as artistas-docentes, hemos ahondado en lo situado, valorando las aportaciones que Donna Haraway ha entregado sobre los conocimientos situados desde una perspectiva feminista. Para esta pensadora, los conocimientos situados surgen a la voluntad de trascender el debate de realismorelativismo, donde el sujeto se puede conocer desde ningún lugar o desde cualquier lugar (Balasch y Montenegro, 2003). Este modelo de objetividad epistemológica propone la parcialidad y localización del conocimiento -evitando los efectos totalizantes de las perspectivas anteriores-, mediante la solidaridad política que se da entre las localizaciones sociales. Este reconocimiento de parcialidad lleva a la conexión y articulación con otras localizaciones. En consecuencia:

La justificación de una creencia como verdadera refiere a la situación del agente de conocimiento; para un sujeto puede estar justificado y ser verdadero lo que para otro no lo es. No hay un punto de vista objetivo, neutro y ajeno desde el cual alcanzar la realidad (...) Cualquier sujeto conoce siempre desde un sistema, desde un lenguaje, a partir de ciertas premisas, en función de unos intereses, en relación con unas expectativas, etc. Todos estos condicionamientos influyen en la interpretación de la realidad que vamos a reconocer como conocimiento (Haraway, 1999, p. 224 en Guzmán, 2015, p. 42) 
Desde este punto de vista los saberes se encarnan, los/as sujetos se multiplican en un espacio determinado y la producción del conocimiento se produce a través de la conexión parcial y múltiple de estas posiciones. En este sentido, pensaremos que el conocimiento y las subjetividades de los/as artistas-docentes se genera en el hacer de sus experiencias artísticas y pedagógicas, un hacer que está situado en la acción y que está cargado de sus intereses, deseos y lenguajes. Esto lo pensaremos como un modelo epistemológico, donde la producción de conocimiento y subjetividad se orienta hacia las responsabilidades éticas y políticas en un contex to de acción. Desde este modelo epistemológico, consideramos que los conocimientos situados son relevantes a la hora de hablar del posicionamiento situado en la construcción de las subjetividades de los/las artistas-docentes de la Región de los Lagos, porque enseñan nuevas formas de concebir los saberes artísticos pedagógicos, los que están imbricados con la experiencia ontológica de quienes son artistas-docentes.

Por ello, lo situacional del profesorado de artes implica pensar en lo ontológico no como un aspecto que refiere solo a la experiencia vivida como artistas y docentes, es decir, dos vivencias únicas y realidades aisladas de ser artista y docente. Por el contrario -y como señala Karen Barad (2003)-, lo ontológico es relacional, no es aislado y no puede desvincularse de las diversas dimensiones de la experiencia, del cuerpo, territorio o el deseo. En este sentido, pensar en subjetividades situadas conlleva entender que la experiencia fluida de ir siendo artista-docente se va articulando como un espacio múltiple, donde estas localizaciones artísticas y pedagógicas se van entrecruzando y tornando híbridas (Hall, 2010). Desde este lugar, comprendemos lo onto-episte-metodológico del profesorado de artes visuales como un desborde y cruce de experiencias y también un tejido de relaciones hilvanadas por lo discursivo, matérico, activo y contextual de quienes van siendo artistas y docentes a la vez. No pensamos lo ontológico del profesorado de artes como algo que está arraigado de manera fija, sino en red, como un fenómeno de quienes se viven desde múltiples experiencias (García-Huidobro, 2018).

Por esta razón que, como han enseñado las feministas materialistas (Nardini, 2014), no es posible separar lo ontológico, de lo metodológico, epistemológico y ético (Barad, 2007), ya que el cómo van siendo y viviéndose las/os artistas-docentes a la vez (ontológico), no puede desvincularse de la forma en que enseñan y realizan creaciones artísticas (lo metodológico). Esto nos permite ver los sentidos que generan en sus prácticas artísticas y docentes (epistemológico) como saberes, y donde entenderemos la construcción de sus subjetividades como un desplazamiento de sus conocimientos situados; sus experiencias artísticas y docentes.

A modo de contextualizar de mejor manera lo señalado, en el siguiente apartado se describe el análisis desarrollado en los grupos focales, se presentan las categorías y se explican con relatos de los/as participantes. En los resultados se manifiesta una construcción de subjetividad que encarna un sentido onto-episte-metodológico del/la artista-docente, donde se imbrican las experiencias artísticas-docentes y desde allí se devela un sentido social que nutre políticamente a dichas subjetividades.

\section{Metodología}

El proyecto se desarrolló desde un diseño emergente y utilizó una metodología mixta, que en su primera fase fue cuantitativa y luego cualitativa. En la primera etapa cuantitativa se tomaron cinco dimensiones para construir variables y escalas de valor en relación a sus 
experiencias artísticas y docentes. Las dimensiones abarcadas en la primera parte del estudio fueron consideradas como aquellos aspectos que influyen en la conformación identitaria de los/as artistas-docentes y permitieron dar orden y sentido al instrumento de recogida. Las dimensiones seleccionadas fueron: (i) la formación y trayectoria profesional, (ii) características de la práctica artística, (iii) conflictos de la práctica artísticadocente, (iv) necesidades de la práctica artística-docente, y por último (v) aportes al desarrollo cultural de la región. A partir de estas dimensiones se conformó una encuesta virtual en Google Forms. El instrumento de recogida se compuso por un total de 21 preguntas con respuestas abiertas, múltiples y selectivas, las que estaban organizadas según las cinco dimensiones de la identidad profesional docente del profesorado de artes. Una vez construido el instrumento, fue validado por dos expertos en el área de educación artística nacional. Se difundió a través de diversas bases de datos y medios de difusión. El instrumento fue contestado por 97 profesores/as de artes visuales provenientes de diversas instituciones educativas del territorio -públicas, privadas, rurales y urbanas-, constituyéndose como una muestra no probabilística, sino que por conveniencia $(50 \%$ provincia de Llanquihue, $36,6 \%$ provincia de Chiloé, $11,2 \%$ provincia Osorno y 2,2\% provincia de Palena).

Posteriormente, la información obtenida fue analizada mediante el programa de análisis estadístico SPSS y se generó una matriz de datos, cruces y variables entre dimensiones. Tras realizar la matriz desarrollamos una interpretación exploratoria, basada en el análisis descriptivo de cada variable y estadística. Esto nos permitió una mayor comprensión del fenómeno estudiado. Dichos resultados (García-Huidobro y Ferrada, 2020) ayudaron a conocer los principales elementos de la formación y la trayectoria del profesorado de artes, sus dificultades y necesidades para el área de enseñanza, lo que permitió orientar la segunda etapa.

Un elemento que nos llamó la atención sobre los resultados de la encuesta, y que se transformó en el eje de la segunda fase cualitativa, fueron las percepciones sobre las características de las prácticas artísticas de los/as participantes. Nos pareció significativo que el $84 \%$ de los/as artistas-docentes encuestados considerara que su hacer pedagógico, es decir el desarrollo de talleres y/o clases de artes, identificara a su práctica artística. Esto nos llevó a preguntarnos por el significado del compromiso educativo como un elemento que es parte de su desarrollo artístico y en qué medida dicho hacer apunta al giro sobre la propia concepción de las artes y el rol tradicional del artista (Rogoff, 2011).

Con estos antecedentes y preguntas, la segunda fase cualitativa fue pensada como un lugar de encuentro entre subjetividades artísticas y docentes, donde los/as participantes pudiesen conocerse, dialogar y además aprender para repensar sus prácticas desde herramientas artísticas. Para ello se convocó al mismo segmento de población que participó en la primera fase cualitativa. De los 97 participantes de la encuesta, 48 asistieron a los grupos focales de manera voluntaria, constituyendo nuestra población objetivo por un muestreo no probabilístico por conveniencia, donde participaron docentes de artes de las provincias de Osorno, Llanquihue y Chiloé, de escuelas rurales y urbanas, públicas y particulares.

Con esta población se realizaron cuatro grupos focales y en cada mesa se dialogó en torno a las siguientes preguntas: ¿Cómo mis clases o experiencias docentes son parte de mi producción artística? ¿Qué tipo de proyectos artísticos y pedagógicos he realizado donde he vinculado mi experiencia como docente? ¿Por qué considero relevante (o no) vincular 
el quehacer artístico personal con mis experiencias como docente? ¿Cómo mi práctica artística y pedagógica es un aporte para la cultura y la región de los Lagos? Dichas preguntas buscaban dar respuestas al tercer y cuarto objetivo específico de este estudio y con ello conocer con mayor profundidad sus subjetividades.

En los grupos focales nos interesó que los/as participantes pudieran compartir sus experiencias docentes a través de sus historias personales y el relato de sus proyectos artísticos pedagógicos, pues, como cuenta Donna Haraway (1997), las historias son parte intrínseca de las prácticas narrativas, lo que para ella significa que "contar cuentos es intrínseco en las prácticas de las ciencias de la vida” (p. 125). Las historias -explica la autora- no son simplemente nada. Por el contrario, las prácticas narrativas constituyen parte importante de lo que ella llama "semiosis de la creación-construcción de los conocimientos biológicos" (p. 125). En este sentido, consideramos que lo dialogado en dichos encuentros fueron prácticas de saber relevantes, pues, sus prácticas narrativas, provenientes de sus lugares sociales, son formas de construir subjetividad.

Posterior a los grupos de discusión se analizaron los relatos compartidos con el software Atlas. Ti, a través de una codificación axial, donde se fueron agrupando los relatos que -a nuestro parecer- aludían a sus formas de situarse en y entre las prácticas artísticas y pedagógicas y que daban cuenta de elementos relevantes en sus subjetividades.

En el siguiente apartado nos situamos en la noción de subjetividad docente y su vínculo con el quehacer de artistas-docentes, desde una visión onto-episte-metodológica. Luego se explican las tres categorías de análisis, como aquellos conceptos que nos ayudaron a entender cómo los/as artistas docentes van conformando sus subjetividades y su aporte social y cultural.

\section{Resultados: Prácticas artísticas-docentes situadas, donde lo artístico es un medio para el cambio}

La pregunta que orientó esta investigación fue cómo los/as artistas-docentes van conformando sus subjetividades y cómo dicho proceso es un aporte social y cultural. Para ello, la segunda fase cualitativa que se realizó a través de los grupos focales fijó su mirada en el tercer y cuarto objetivo específico de este estudio. A saber: Explorar cómo el profesorado de artes vincula sus proyectos artísticos-educativos con las necesidades del entorno y, describir las características que componen las prácticas docentes y artísticas de dichos docentes y analizar cómo impactan en el desarrollo social y cultural de la región. Para ello, las preguntas de los grupos focales fueron ¿Cómo mis clases o experiencias docentes son parte de mi producción artística? ¿Qué tipo de proyectos artísticos y pedagógicos he realizado donde he vinculado mi experiencia como docente? ¿Por qué considero relevante (o no) vincular el quehacer artístico personal con mis experiencias como docente? ¿Cómo mi práctica artística y pedagógica es un aporte para la cultura y la región de los Lagos? Dichas preguntas fueron creadas con la intención de que las respuestas y el diálogo se centrara en cómo sus procesos de creación dialogan con lo pedagógico. Sin embargo, al presenciar los grupos focales (y el posterior análisis) pudimos comprender que aquello relevante que emergía en los grupos era del orden de otra cosa. Para identificar y comprender lo que ocurría, nos dispusimos a realizar el análisis intentando entender cuál era el lugar situado de la práctica artística y el de la práctica 
pedagógica, cómo era el desplazamiento de dichos conocimientos situados y hacia dónde les llevaba.

A partir del ordenamiento y agrupación de los relatos sobre el sentido y lugar de sus prácticas artísticas y pedagógicas, pudimos apreciar tres aspectos relevantes y que identificamos como conceptos claves; las categorías: (i) Creación Artística Personal Situada, (ii) Lo artístico y (3) Agente/a de cambio. En la siguiente tabla se muestran las categorías con subcategorías (cuadro 1).

Cuadro 1. Categorización de la conformación de subjetividades de artistas-docentes

\begin{tabular}{|c|c|c|}
\hline $\begin{array}{c}\text { PREGUNTA } \\
\text { INVESTIGACIÓN }\end{array}$ & CATEgoría & SUBCATEGoría \\
\hline \multirow{2}{*}{$\begin{array}{l}\text { Conformación de las } \\
\text { subjetividades de } \\
\text { artistas-docentes y su } \\
\text { aporte social y cultural }\end{array}$} & $\begin{array}{l}\text { Creación Artística Personal } \\
\text { Situada (CAPS) }\end{array}$ & $\begin{array}{l}\text { En el lugar de la práctica } \\
\text { pedagógica } \\
\text { En diálogo con la práctica } \\
\text { pedagógica }\end{array}$ \\
\hline & Lo artístico & $\begin{array}{l}\text { Transformación } \\
\text { Mediación }\end{array}$ \\
\hline
\end{tabular}

Fuente: Elaboración propia.

Valoramos, además, la segunda categoría de Lo artístico como una articulación entre la primera y tercera categoría, puesto que se transforma en un medio para generar cambios y transformaciones sociales y culturales relevantes. Desde este lugar, pudimos comprender que lo onto-epis-metodológico estaba incorporado en sus formas de ir siendo artistas-docentes, puesto que a través del análisis de sus relatos observamos que la práctica artística, propia de cada artista-docente, no puede desvincularse del estar en el aula y en la escuela, y a esto llamamos: lo situado. En los relatos, también pudimos apreciar que el profesorado de artes, cuando entra al contexto educativo, transforma su creación artística personal en una que es situada en lo pedagógico. Desde aquí desprendemos, entonces, que la práctica artística situada se localiza en y con la práctica pedagógica. Por ello, la manera de situar sus prácticas artísticas, en el lugar y en diálogo con la práctica pedagógica, transforma a dicho hacer artístico en otra cosa: en lo que denominamos como lo artístico y que se vincula más como una herramienta metodológica de mediación y transformación. Esta forma de utilizar a las artes y de situarse como artistas-docentes, nos llevó a vislumbrar su posición como agentes/as de cambio y sujetos/as activas que abren posibilidades en el estudiantado. Por ello, entendemos sus subjetividades como los desplazamientos que hacen entre sus conocimientos y experiencias situadas entre lo artístico y pedagógico, lo que se va transformando en elementos posibilitadores. Explicamos estos desplazamientos en el siguiente diagrama (figura 1).

Las tres categorías que se proponen muestran una temporalidad y se dan como un proceso que es dado por el contexto educativo donde cada artista-docente trabaja. Es relevante señalar que el contexto educativo no fue pensado como categoría, ya que el medio y contexto educativo es un espacio transversal que influye para que la creación artística personal viva un proceso de cambio hacia lo artístico, lo cual transforma a los/as artistasdocentes en agentes de cambio. Sin embargo, hay que recalcar que lo situado, es decir el contexto educativo del profesorado de artes visuales, es intrínseco en la conformación de sus subjetividades. Es en estos espacios donde los procesos de agenciamiento adquieren un sentido. Por lo tanto, el contex to educativo es una dimensión política que engloba y da 
sentido al cruce de categorías, más no una categoría de análisis en sí misma. A partir de lo expuesto se profundiza y explica cada categoría señalada.

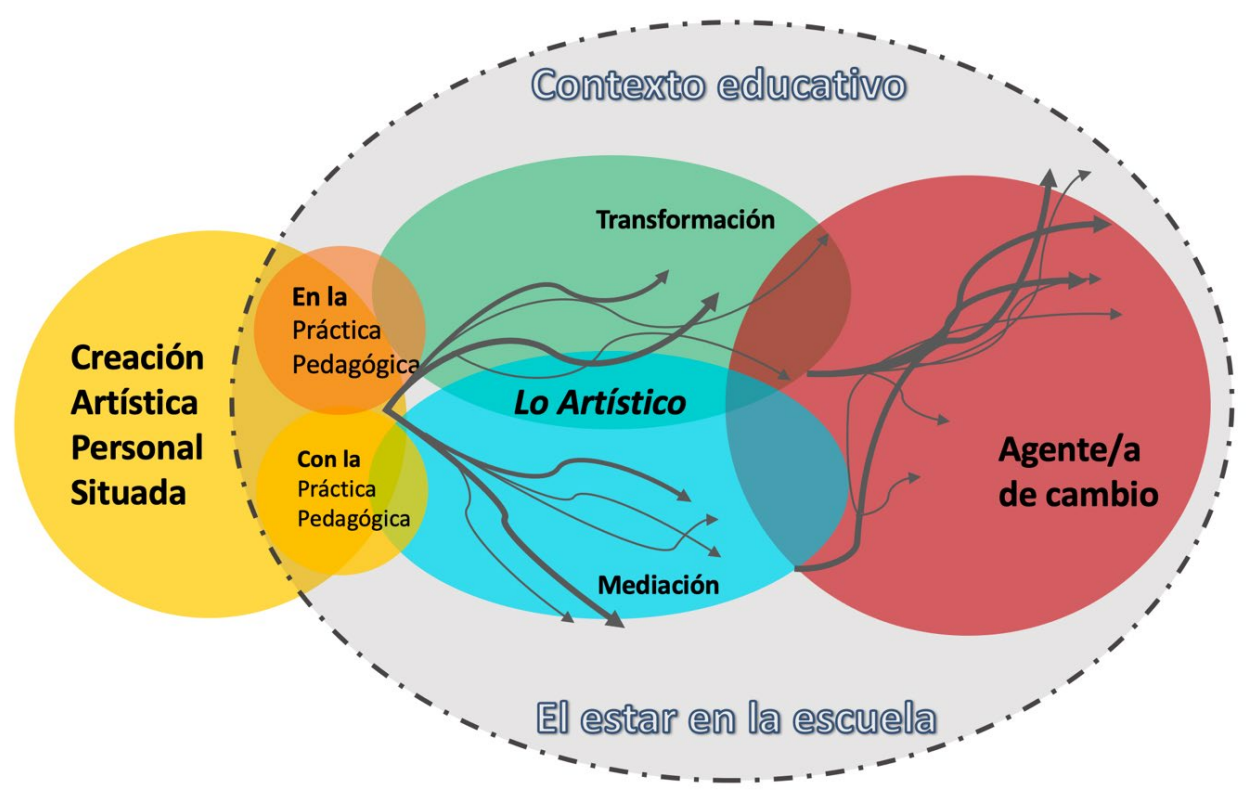

Figura 1. Cruce de categorías en el contex to educativo

Fuente: Elaboración propia.

\subsection{La Creación Artística Personal Situada (CAPS)}

A través de esta categoría se alude a cómo los y las artistas-docentes refieren a su desarrollo como artistas cuando se les pregunta por sus prácticas artísticas o proyectos creativos. Es interesante observar que en los relatos del profesorado el proceso creativo y artístico personal siempre es situado en el plano o espacio pedagógico y no como un tipo de arte que es aislado, individual o de taller. A partir de aquí se pudo evidenciar dos formas de aludir sobre sus procesos artísticos y creativos personales. Por un lado, cuando la CAPS se sitúa en el espacio pedagógico (ontológico), se puede observar que los/as artistasdocentes llevan parte de la experiencia artística personal al espacio pedagógico y, por otro lado, se pudo evidenciar que cuando la CAPS se sitúa en diálogo con lo pedagógico (epistemológico) ocurre un proceso interesante, relacionado con una desapropiación o despoje de lo artístico individual, para ponerlo en sintonía con la experiencia o necesidades del aula.

En cuanto al espacio pedagógico (ontológico), pudimos ver que la CAPS está en constante diálogo con el lugar de la práctica pedagógica, donde la práctica, creación y/o interés artístico que los define o lleva a concebirse como artistas, se manifiesta en sus prácticas pedagógicas. Esto se evidencia a través de la entrega de técnicas y temáticas, donde pueden "traspasar" sus intereses y/o experiencias como artistas. En cuanto al espacio pedagógico (epistemológico) se manifiesta una desapropiación de lo artístico como proyecto individual y entonces la experiencia creativa se pone al servicio o bien nutre la práctica pedagógica. Así, la creación se dispone hacia el aprendizaje del estudiantado. Los conocimientos de la disciplina artística a la que cada uno/a se dedica, dejan de ser un proyecto individual y se sintonizan con los procesos pedagógicos. Lo que se enseña, entonces, son formas de relacionarse con el mundo a través de la creación artística. 


\title{
4.1.1. Creación Artística Personal Situada en el lugar de la práctica pedagógica
}

En 2002, la artista Cubana Tania Bruguera comienza con su proyecto artístico público “Cátedra Arte de Conducta”, el cual funciona hasta 2009 como una escuela de arte alternativa, donde se enseña cómo transformar la sociedad a través de un arte socialmente comprometido. En su proyecto, Bruguera toma a la educación como un medio artístico, donde su práctica artística se despliega como pedagógica. La experiencia de Bruguera nos parece particularmente interesante nombrarla, dado que, en los últimos años, el giro educativo en las artes (Rogoff, 2011) nos ha invitado a observar el rol de la educación en el ámbito artístico. Desde este nuevo diálogo entre las artes y la educación, hemos observado que algunos/as artistas-docentes también buscan llevar sus intereses y deseos creativos al aula y, en este sentido, parece interesante observar las modificaciones que dicha intención de creación puede vivir al ser realizada con el estudiantado. En este sentido, algunas artistas-docentes del estudio nos cuentan:

\begin{abstract}
Como se toma el tema de reciclaje y medio ambiente empezamos a observar, analizar, para ver el tema del entorno, y de ahí surgió en cierta forma, y gracias a los alumnos, la producción de una obra propia mía, que después llevé al ejercicio con estudiantes ahora en marzo, que era en base al cianotipo, que es una técnica de emulsión fotoquímica, que traspasará la silueta de la imagen o del objeto, del desecho que recogimos en la playa ya que yo trabajo en un liceo rural, a $17 \mathrm{~km}$ de acá. Entonces ellos recolectaron, separamos basura, juntamos elementos naturales que son las hojas las ramas, todo lo que conforma el espacio. (Participante 4)
\end{abstract}

Entonces, como que me he enamorado tanto de la educación que lo estoy llevando a mi disciplina, como hacer documentales sobre eso. Sobre la educación rural específicamente. (Participante 30)

$\Upsilon$ de hecho desde ese afán, de esa obsesión que tengo con el óleo, logré que aprendieran a pintar oleo. Me sali de todos los contenidos, no me importó. Inventé en el libro jajaja y todo un nivel de segundo año medio aprendió a pintar. (Participante 11)

Lo que estas artistas-docentes nos relatan es, al igual que la intención de Tania Bruguera, la necesidad de llevar su deseo e interés de creación al espacio del aula. ¿Cuál es la experiencia situada a la cual referimos? En los relatos anteriores nos hablan de obsesión y enamoramiento, y observamos que se sitúan a ellas, desde las artes, como punto de incardinamiento situado en donde empieza el deseo de enseñanza. Esto nos parece fundamental y se relaciona con lo que la pedagogía de la diferencia ha llamado el partir de sí.

Como nos ha enseñado Nieves Blanco (2006), "los docentes no enseñamos una materia, sino nuestra relación con ella y también nuestra relación con cada alumna y cada alumno" (p. 176). Rescatamos la idea de cómo el profesorado puede trasladar su sentido e interés creativo al aula, sin dejarlo aislado en el espacio de taller individual y tomando así un sentido social y relacional, para que éste pueda ser transformado desde la relación pedagógica y se abra a nuevas posibilidades. Desde aquí pensamos en la relevancia que adquieren los procesos artísticos, creativos y culturales que desarrollan los/as artistasdocentes con el estudiantado en el aula, y no como una oportunidad para desarrollar sus proyectos artísticos individuales, sino como un cruce epistemológico y ontológico (GarcíaHuidobro, Viveros y Bahamonde, 2020), que nos permite ir "más allá de los límites impuestos por quienes consideran que es el arte” (Hernández, 2009, p. 309) y el circuito artístico.

A partir de aquí, proponemos que la creación artística que es situada en el espacio pedagógico, entre artistas-docentes y estudiantes, son producciones culturales que, como 
expresan María Acaso y Clara Megías (2017), "quedan situadas al mismo nivel de reconocimiento social que los proyectos de artistas y curadores” (p. 135).

\subsubsection{Creación Artística Personal Situada en diálogo con la práctica pedagógica}

Grant Kester (2011) llama "arte dialógico" a la posibilidad de generar otras formas de relación entre las personas que son partícipes en las prácticas artísticas. A partir de esta idea, volvemos a señalar cómo los/as artistas-docentes involucran en su quehacer docente sus ideas e intereses artísticos y creativos, poniendo al centro, esta vez, el diálogo que estas maestras establecen cuando piensan la relación de su proceso creativo con el de su hacer en la escuela:

Bueno, tal como algunas dijeron, yo creo que es inseparable lo uno de lo otro [refiere a su práctica artística con la pedagógica] y aparte que, cuando tú estás enseñando, también siento que estas creando paralelamente. (Participante 22)

Con estas palabras, esta artista-docente nos recalca la necesidad ética-onto-epistemetodológica de vincular su hacer docente con el artístico, pues, cuando señala que al estar enseñando también se está creando, nos habla de una relación donde se imbrican procesos y saberes que son rizomáticos e híbridos. Además, creemos que cuando ocurre aquel proceso de arte dialógico que propone Kester (2011), emergen elementos que muestran lo nuevo y transforman al/la artista-docente en un/a posibilitador/a de experiencias:

Creo que tiene que ver con esa carencia, de que una no puede de repente poder procesar y poder expresar en nuestra propia obra, lo que pueden a lo mejor lograr los niños, (...) yo pienso que es una carencia de nosotros como artistas, de poder expresar eso y lo traspasamos a nuestros alumnos de alguna manera, porque yo en los talleres de jornada escolar completa... allá a los niños los llevo al mar, y los he llevado a algunas exposiciones sobre todo de carácter surrealista, y porque me interesa mucho esa parte, porque si voy a explotar la parte patrimonial sobre todo de Chiloé, donde hay mucha mística, donde hay mitología etc., los llevo por ese lado, y han salido obras maravillosas, que han tenido que ver con la contingencia incluso, de lo que está sucediendo a través de la iglesia, que se yo, y lo han llevado a un ámbito bastante surrealista y bonito, de.. con una expresión propia de ellos, que a mí me han dejado ¡Plop'? (Participante 38)

La artista-docente nos habla de sus carencias como artista y cómo sus imposibilidades la llevan a volcar el deseo de creación en el estudiantado. Estas ideas nos invitan a pensar en

la diferencia entre el diálogo comunicativo y el diálogo analítico que explica Elizabeth Ellsworth (2005). Esta académica cuenta que el diálogo comunicativo no enseña realmente, porque está mediado por estructuras de poder prefijadas que determinan los roles entre profesorado y estudiantado. Por ello, la idea es que un diálogo nos pueda llevar a un terreno nuevo y desconocido, lejos de lo preestablecido. Para esta autora, ese tipo de comunicación dialógica es el diálogo analítico, el que no pretende una comprensión plena o un control sobre el estudiantado, y por ende abre paso a lo nuevo; a la enseñanza más profunda.

\footnotetext{
${ }^{2}$ Condorito es la historieta cómica más popular en Chile, originada en 1949. Una característica peculiar de estas historietas es que, al término de cada historia, uno o varios de los personajes se desmayan o caen al suelo como víctimas de una situación vergonzosa o comentario ridículo. Esa última imagen viene acompañada de una onomatopeya -que exclama ¡PLOP!-, como una forma de éstos de pedir explicación o quedar desconcertados.
} 
En este sentido, creemos que los/as artistas-docentes pueden generar un diálogo analógico con su estudiantado cuando ven, en su posibilidad de enseñar, una carencia, puesto que los/as puede llevar -como muestra la participante $38-$, a despojarse de las estructuras prefijadas, y más bien desde su interés posibilitar al estudiantado a crear. Esto, como nos relata la participante, trae sorpresa y entonces se abre paso a lo no pensado, a lo que se puede aprender con el estudiantado desde la ignorancia y lo contingente. Es un terreno donde el profesorado junto a sus estudiantes transita por la incertidumbre y la sorpresa. A esto, Dennis Atkinson (2016) ha llamado poiesis, y alude al riesgo de ir aprendiendo con los y las otras a través de la experiencia artística situada.

\subsection{Lo artístico}

La segunda categoría de análisis es lo artístico y alude a los cambios que pueden ocurrirles a las prácticas artísticas individuales cuando se convierten en modos de ser, hacer y conocer, en diálogo con otras experiencias, como por ejemplo las pedagógicas. Según expresa Adiana Raggi, "la producción artística no es hoy en día -y en realidad nunca lo ha sido- un lugar de producción y venta de objetos, es un lugar de producción de conocimiento del mundo en el que vivimos" (Raggi en Dávila, 2018, p. 116). En relación a ello, con esta categoría pensamos el arte más allá del arte por el arte o como una instancia propositiva y lo llamamos lo artístico, haciendo alusión a su capacidad como medio para conocer, afectar e impactar socialmente. Si Andrea de Pascual y David Lanau plantean que el arte "es una herramienta de actuación, una forma de pensar y hacer capaz de transformar la educación y los mecanismos de impacto social” (De Pascual y Lanau, 2018, p. 70), entonces, a través de dicha afirmación y los relatos de los/as participantes de este estudio, dejamos de pensar el arte como un objeto/sujeto y lo entendemos como un agente y un medio.

\subsubsection{Lo artístico como transformación}

A partir de lo descrito sobre lo artístico, consideramos que esto es una acción o actividad que, como señala Juan Gil (2018), produce algo nuevo. Esta novedad, también Dennis Atkinson (2016) la ha explicado como la fuerza del arte, donde refiere a la energía e ímpetu que lo artístico nos entrega para transformar, generar nuevos saberes y posibilidades. Así, lo artístico en esta categoría no es pensado cómo un agente que transforma la realidad educativa, sino como un acontecimiento. Se percibe un aparecer que permite la emergencia de algo distinto que es posibilitador de algo nuevo. En relación a ello, el curador Luis Guerra se pregunta: “ ¿es el acontecimiento una transformación al nivel de percepción de la realidad o es efectivamente una transformación en el suceder de las cosas propias" (Guerra, 2017, p. 62). Su pregunta, a su vez nos permite cuestionar la experiencia de los/as artistas-docentes para revisar, en qué medida los acontecimientos que se promueven en los espacios pedagógicos abren posibilidades de reconocimiento en el hacer del estudiantado.

Es muy importante poder presentar lo que los niños hacen, yo hice una exposición en el colegio el año pasado. En el taller de jornada escolar completa, tomé los cuadros, como yo les decía ahí los puse en un bonito pasparteu (...) fueron como 32 obras de ellos y se sentían, pero inflados, porque yo les dije: ustedes tienen que decir lo que hicieron. Ellos se ponían al lado de sus creaciones, ellos explicaban a los que llegaban, y fue maravilloso. (Participante 5)

Esta artista-docente redefine el espacio educativo como arena política, generando nuevas posibilidades para el estudiantado donde se pueden reconocer y revalorizar. En este 
sentido, nuestra pregunta no es en qué medida lo artístico transforma a la realidad, sino cómo lo artístico en sí se abre y se transforma en posibilidad. Estas nuevas posibilidades para el estudiantado son orientadoras para generar percepciones de reconocimiento y más participativas en su entorno (Sales, Traver y Moliner, 2019), y es aquí donde consideramos el rol transformador de las artes.

Yo también les enseño a creerse el cuento porque yo también soy artista (...) es un colegio de carácter cristiano, vulnerable es chiquitito, en promedio fluctúa entre 100 12 alumnos [por curso], por esa parte también es más corto llegar a cada uno e igual llevar un seguimiento más personalizado, con hacer también sus gustos, sus inquietudes, sus fortalezas y debilidades (...) en el proceso de las artes los chicos de quinto no saben mezclar colores de partida y vamos por parte, yo también voy con ellos, yo también voy descubriendo cosas nuevas, vamos juntos con cositas técnicas. (Participante 21)

Sin embargo, me abro a lo otro que yo he ido aprendiendo. Porque en el currículum también hay harto objetual y también encuentro que es muy ajeno a los niños (...) $Y$ respecto a lo que ellos o las artes visuales me han entregado a mi como asignatura, yo podría decir que es como abrirme a otros, a otros estilos, comprender que no se trata de bonito o feo si no de expresión. Porque los niños dicen: Es que no está bonito... y es que no se trata de que es bonito o feo jSe trata de que tú te expresas! (Participante 12)

Nos parece interesante subrayar como ambas artistas-docentes no enfocan lo artístico como un logro, no persiguen un resultado a través de las artes, sino una posibilidad para aprender, conocerse y que el estudiantado se valore a través de promover experiencias motoras de forma relacional. Esto las lleva a involucrarse más allá de lo artístico como aspecto curricular, sino de lo artístico como aspecto democratizador y de revalorización personal. Por otra parte, lo transformativo no solo es unidireccional ya que involucra al profesorado. Esta redefinición del espacio educativo desde lo artístico también les compete, porque les posibilita aprender con el estudiantado.

Vinculamos los relatos de las participantes con los ensayos de Luis Guerra (2017), sobre la inexistencia del arte. En estos, el autor nos propone que "existen procedimientos artísticos indomiciliados" (p. 40), con lo que explica la existencia de diversas formas prácticas y procedimientos que exceden el campo artístico y la rúbrica del Arte, ya que son de otro orden. Con la idea de inexistencia del arte, Guerra habla de otra experiencia que llama arte emancipador y que nos permite pensar los modos de existir para aprender a ser.

En relación a ello y como nos enseñan las participantes, el tipo de acontecimientos artísticos que promueven permiten emancipación y, a su vez, se sitúan en un enfoque artístico que ha explicado Imanol Aguirre (2005), donde lo artístico se vive como una experiencia contingente y de posibilidad que permite comprender para luego transformar la experiencia del arte en la escuela, y donde las obras de arte o las técnicas son medios y herramientas para generar nuevas comprensiones de ellos y ellas mismas. Creemos que lo artístico vivido en dichos acontecimientos encuentra su domicilio fuera del campo artístico tradicional, porque no pone el foco en la creación o resultado, sino en el impulso de crear nuevas relaciones y aprendizajes desde una redefinición del contex to educativo que oriente hacia aprendizajes compartidos y significativos para el estudiantado.

Luis Guerra, también llama infrapolíticas a la "acumulación invisible de acciones, procedimientos, estrategias que trabajan resistiendo, emancipando (...) estas acciones de arte a las que refiero como inexistentes componen modos de sustracción constitutiva" 
(Guerra, 2017, p. 46-47). Infrapolíticas son las prácticas políticas cotidianas no referidas a discursos políticos, sino a acciones que disrumpen y desestabilizan el sistema. Desde aquí entendemos entonces que las prácticas y actividades artísticas sin domicilio fijo -y que cuestionan el sistema del Arte- son infrapolíticas. De esta manera, entendemos como los/as artistas-docentes reconocen la labor de crear conciencia a través de las artes y esto se observa como acumulación invisible de acciones que generarán cambios, donde el estudiantado se identifica con estos cambios porque son propios de la realidad que ellos y ellas viven día a día, que no pertenecen a un discurso, sino que son reflexiones onto-epistemetodológicas.

\subsubsection{Lo artístico como mediación}

Deleuze (1995) ha explicado la necesidad de que los procesos creativos y las prácticas artísticas acontezcan desde mediaciones, entendiéndola como la posibilidad de vincular dos o más cosas, sujetos/as. Nos explica que “toda la creación sucede en los mediadores. Sin ellos no pasaría nada. Se puede tratar de personas (...) Yo necesito mis mediadores para expresarme, y ellos no podrían llegar a expresarse sin mí: siempre es un trabajo en grupo” (p. 125). Lo que nos explica a través de estas palabras, es que si pensamos que las creaciones artísticas de los/as artistas-docentes ocurren en y con la práctica pedagógica, entonces en el vínculo y trabajo conjunto entre docente y estudiantado se genera la mediación como un acto de creación y esto es una práctica diferenciadora.

Pero cada experiencia de trabajo es diferente, en el caso de estas niñas, yo también me
planteo cada día, cuál es la mejor manera de trabajar con ellas, con sus personalidades,
que tratamientos están conociendo... se están soltando igual y tengo que valorar eso
en su propio aprendizaje personal, como ya se conocen, eso va a dar pie a un buen
lugar de trabajo también, como que no puedo llegar y decirles: ¡Ya, silencio, tenemos
que poner atención! Porque tampoco es la idea que estén contenidas y restringidas si
vienen de un proceso del colegio donde están así toda la mañana...entonces llegan ahí
y quieren pintar, pero quieren también jugar entre ellas. Siento que soy yo la que tengo
que encontrar la manera de trabajar bien con ellas de acuerdo a sus personalidades,
más que ellas adaptarse a mi forma de trabajo. Entonces, eso son como los desafíos
que uno se plantea cada vez que enfrentas un grupo nuevo, por eso a mí me gusta
trabajar procesos más largos, de un año mínimo porque ahí realmente tú tienes la
posibilidad de conocer a tus estudiantes y de sacar el mejor provecho de ellos cuando
ya los conoces. (Participante 39)

Lo artístico, en este caso, es vivido como mediación en dos sentidos. El primero es más evidente, y se da por el vínculo entre artista-docente y alumnado, creando una relación social entre ambos (Gell, 1992) y que permite que se generen los acontecimientos artísticos. El segundo sentido alude a la relevancia que la artista-docente entrega a cultivar la relación pedagógica, a conocer al estudiantado y dejarse dar y afectar por las relaciones. En ello se manifiesta lo artístico, estando también presente en las relaciones como formas de mediación. Dejarse dar, explica Nieves Blanco (citada en Sofías, 2002, pp. 116-117) "es mostrarse abierta a errores, a las contradicciones, a los conflictos, pero también es dejarse afectar por ellas y ellos, aprender con y de las y los estudiantes concretos". En ese dejarse dar se requiere valorar la singularidad del otro/a y su reconocimiento, para que lo artístico tenga sentido de trascendencia en el quehacer docente.

Así me aprovecho harto de no ser profesora cachai y la artista entre comillas, dentro de la sala, entonces muevo mobiliario, eso es lo primero. Entonces siempre ese gesto de mover el espacio, cambiarlo, ya en los niños genera como una cosa. (Participante 23)

Como ha señalado el curador Oriol Fontdevila (2018), 
El arte no es solamente aquello que es mediado por un agente externo, sino que el arte actúa también por sí mismo en tanto que agente de mediación. Esto es, las proposiciones artísticas no esperan pasivas a entrar en acción por medio de la actividad de un agente externo, sino que el arte es también un agente que tiene capacidad para desarrollar su propia actividad, condicionar el despliegue de redes de su entorno, e incluso incidir en la formación de asociaciones entre agentes humano y no-humanos. (Fontdevila, 2018, p. 51)

Vinculamos las palabras de Fontdevila con las de la participante 23, para explicar que lo artístico, en tanto mediación, no se da como un proceso autónomo, obvio o evidente, o solo por la existencia de un vínculo entre dos agentes. Es necesario que existan acciones consientes que la promuevan como, por ejemplo, cuando la participante 39 expresa: "tengo que encontrar la manera de trabajar bien con ellas de acuerdo a sus personalidades" o bien cuando la participante 23 señala: "ese gesto de mover el espacio, cambiarlo". Lo artístico, en ambos casos no refiere a la actividad artística propiamente tal, sino al acontecimiento, el que alude a todo lo que la mediación genera, produce y abre. La mediación -explica Oriol Fontdevila (2018)- nos permite un pensamiento diferencial, ya que nos lleva a nuevos espacios, ideas y formas de acción artística.

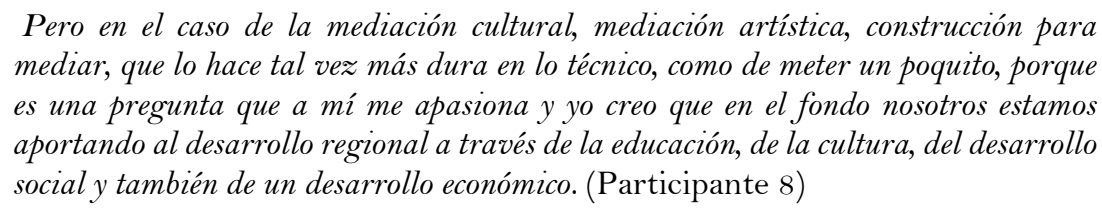

Nos parece interesante la reflexión de la participante, quien reconoce cómo la mediación, en tanto proceso, es un aporte que trasciende lo escolar y se transforma en prácticas transformadoras. Asimismo, valoramos su reconocimiento sobre la idea de "construcción para mediar", pues, consideramos que también es necesario mediar para construir, ya que observamos que en los/as artistas-docentes lo artístico emerge como una posibilidad de la mediación.

\subsection{Artistas-docentes como agentes/as de cambio}

La pensadora Marina Garcés (2013) reflexiona sobre la novedad en educación y su carácter emancipador y se pregunta “¿por qué los artistas y los activistas quieren ser, ahora, educadores” (p. 85). Años más tarde, a ella responden María Acaso y Clara Megías (2017), explicando que dicho fenómeno se genera dada la necesidad de ir más allá de lo propositivo, para generar prácticas artísticas y culturales que sean socialmente transformadoras y sean un motor de cambio social. No es precisamente que se enseñe artes dentro de un contexto educativo formal, sino que desde lo artístico se promueva una experiencia donde el profesorado de artes sea mediador e impulse procesos transformativos. Es desde aquí donde creemos que se convierten en agentes/as de cambios.

En relación a ello, con esta categoría aludimos a cuando los/as artistas-docentes reconocían -de manera consciente y literal- su hacer como mediador y transformador, promoviendo impacto real en los territorios donde trabajan y viven para afectarlos.

Yo he estado en muchas partes exponiendo mi trabajo, soy premio nacional maestro artesano 2013 (...) Entonces nosotros somos un tremendo aporte para la vida de los niños, en el sentido de que ellos tampoco tengan límite de poder crear, para que ellos se fortalezcan como ser humano. Porque vivimos en una sociedad que está todo el rato limitándote. $\Upsilon$ en el arte no hay límite, y ese eso es lo principal, la libertad de expresión, la superación personal que uno se da. (Participante 19) 
En el 2016 publicamos un trabajo que es una recopilación de videos de vivencias de 22 localidades rurales de la comuna de puerto Montt y que está enfocado en el tema que es que en los campos uno ve mucho abandono, de ahi me motivo a hacer este trabajo, hicimos (...) Sabes que hubo un impacto social, nosotros se lo entregamos a las autoridades, huvo un impacto social de un trabajo donde se deja visualizar una realidad, un drama, porque la ronda media va para los campos, para el sector La Arena; hacía 4 años que le habían ido a sacar los dientes a todas las mujeres para colocarles las prótesis y nunca más fueron y asi sucesivamente lo que yo pude ver in situ (...) Considero que sí ha habido un impacto en el trabajo de recopilación, por eso considero que nosotros los artistas tenemos, yo personalmente, pero me gustaría todos tuviéramos este rol de poder hacer a través del arte o del teatro, decir lo que está pasando. (Participante 45)

To creo que el aporte que uno hace a la cultura es el ámbito de crear conciencia, de crear, de sociabilizar un enfoque del desarrollo de la curiosidad, del pensamiento, de la imaginación creadora. To creo que por ahí va la cosa (...) Entonces yo creo que uno es un aporte a eso, siempre va a ser un aporte implícito ahi en el trabajo que uno hace muy de abajo, pero va a ser un aporte siempre al desarrollo de la cultura. (Participante 46)

En los relatos anteriores se puede observar una autorización y reconocimiento no solo por el trabajo que realizan, en tanto social, sino que también como agentes/as de cambio que se preguntan por la justicia social, la democratización de la cultura y donde su quehacer se pone al servicio del desarrollo social y cultural. A partir de esto, se plantea a los/as artistas-docentes como productores culturales (Acaso y Megías, 2017), es decir, quienes a través de su hacer docente promueven la cultura y la dotan de significado en la vida del estudiantado. Incluso, como relatan los/as artistas-docentes, traspasando los límites de lo educativo y siendo agentes/as de cambio en todo ámbito.

En 2015, Carmen Mörsch planteó cuatro discursos de educación y mediación artística presentes en las instituciones culturales: el afirmativo, reproductivo, deconstructivo y el transformativo. Este último es explicado como la necesidad de que la educación y mediación en museos sitúe a la institución como un actor de cambio social. Estas ideas, si las trasladamos a la escuela nos llevan a pensar, también, en la necesidad de artistasdocentes que, como productores culturales, se transforman en actores/actrices políticos/as que promueven el cambio social. Este llamado nos parece relevante mencionarlo para evidenciar que los/as artistas-docentes visualizan en ellos/as este hacer y son conscientes del aporte político que entregan, "construyendo conocimiento en un proceso democratizador que otorga un papel de activismo político al profesorado y a las comunidades (Gale y Densmore, 2007, citado en Sales, Traver Martí y Moliner, 2019, p. 178).

El rol de los/as artistas-docentes conlleva una dimensión transformadora de la educación, promoviendo iniciativas comprometidas con el entorno y el contexto social. Lo que hace la participante 45, por ejemplo, es llevar esta noción transformadora de la educación más allá del aula, sacando adelante un proyecto participativo que promueve la capacidad crítica, comprometida con el entorno y generadora de nuevas oportunidades para la ciudadanía (Jiménez, 2014), incorporando una problemática social que convoca a toda la población de un territorio en particular. Ser un/una artista-docente y agente/a de cambio, promueve ver el aula como un espacio compartido desde la creatividad, como una forma de comprender el mundo, desde una postura política que no puede ser, si no es colaborativa entre el estudiantado y la comunidad. "Crear conciencia", como menciona el participante 46, es repensar el espacio educativo, ya no como ese espacio de entrega jerárquica de conocimientos, sino como un espacio de experimentación cultural con enfoque holístico, 
plural y comunitario, enraizado en lo artístico y que se pone al servicio para propiciar cambios en las lógicas y lenguajes territoriales (Sales, Traver Martí y Moliner, 2019).

El territorio es hacedor de agentes/as sociales ya que, desde ese libro abierto, este cuaderno de bitácora (Carbonell, 2001), se toman decisiones políticas para el quehacer artístico. El territorio es el lugar donde el/la agente/a social (el profesorado de arte de la Región de los Lagos) se sitúa en una de las conexiones parciales como postura política para el cambio social, generando una red vinculante con el estudiantado y el territorio y portando nuevas posibilidades y sentidos para/con el contexto que les rodea. Esto evidencia el tejido social que los/las modela para ejercer cambios en el territorio, que son en sí mismos procesos reflexivos desde el hacer artístico situados e imbricados desde las mismas problemáticas de la comunidad.

\section{Conclusiones}

En este artículo se han expuesto los resultados de la fase cualitativa del estudio "Identidades profesionales de lo/as artistas-docentes en la Región de Los Lagos. Transformaciones de lo social en compromiso cultural", que buscó conocer las subjetividades del profesorado de artes visuales de la Región de Los Lagos en Chile y comprender cómo dichas subjetividades contribuyen al desarrollo social y cultural de la región.

Respecto a la configuración de subjetividades de los/as artistas-docentes, se pudo evidenciar la emergencia de tres elementos que identificamos como particularidades relevantes para entender sus subjevidades situadas.

El primer elemento fue comprender que en las subjetividades artistas-docentes hay un cambio sobre el lugar en que se entiende la producción o creación artística personal. Nos parece relevante apreciar que el ejercicio docente modifica la concepción de los artistasdocentes sobre su propia práctica artística, para no concebirla desde el lugar de lo individual, sino que conectado a lo social y situado en el espacio docente. En este proceso, es importante destacar que el cambio surge en la práctica docente y en diálogo con ella, por lo que el contexto educativo es relevante para entender sus subjetividades. Entenderemos, entonces, que el contexto educativo tiene un componente transformador para ellos/as, ya que en estos espacios toman decisiones éticas y políticas sobre sus creaciones artísticas. Es en este contexto donde deciden conectar el hacer artístico a lo social.

En segundo lugar, es relevante mencionar que dichas formas de relatar y percibir sus ejercicios artísticos, al estar en un contexto social y educativo, no aluden a las artes ni a sus capacidades creativas como una creación objetual o de resultados, sino posibilitadora; y a esto llamamos lo artístico. Las artes, entonces, para los/as artistas-docentes se transforman en un espacio nuevo, que es mediador y posibilitador en los contextos educativos.

Por último, el tercer elemento ha sido reconocer que tanto las prácticas artísticas situadas en/con lo pedagógico y que transitan hacia lo artístico mediador y posibilitador, nos llevan a comprender a los/as artistas-docentes como agentes de cambio. Esta idea parece sumamente importante, ya que el quehacer del/la artista-docente es la posibilidad de articular una posición disruptiva para la transformación social, pues, introduce aspectos diferenciales frente a lo que aparenta ser rígidamente constituido en la escuela y genera 
cambios en el entorno y la ciudadanía, porque al ser situadas, comprometen las reflexiones de la comunidad que experimenta las mismas problemáticas como una forma de repensar el mundo.

Estas tres particularidades nos muestran tipos y formas de subjetividades que se generan en un tejido social, dado por el territorio, el contexto educativo y en donde la experiencia de ir siendo artistas-docentes se torna esencial, pues, las formas en que enseñan, la realización de creaciones artísticas y cómo estos saberes se cruzan y generan en sus prácticas artísticas y docentes, develan un carácter y compromiso social con la enseñanza de las artes.

Nos parece relevante finalizar este escrito retomando una pregunta planteada en la introducción, para reflexionar en torno a “qué modelos de investigación en Educación Artística y creatividad social pueden contribuir a un replanteamiento epistemológico de la enseñanza, tanto en su nivel formal como no formal?” (Ossa, 2017, p. 9). Sobre ello, a través de este estudio pareciera quedar en evidencia la necesidad de trascender los modelos y perspectivas de educación artística (Imanol Aguirre, 2005), y que, además, en nuestro país no han permitido un avance sustantivo sobre lo que significa hacer y enseñar artes en Chile. Con este estudio se plantea la urgencia de pensar en modelos de investigación en educación artística que pongan foco en lo social, más que en lo técnico o validación de modelos. Las evidencias de este estudio muestran la necesidad de articular una epistemología de lo situado en la educación artística y su área de investigación, y que sea promovida por un profesorado que pueda observar y reconocer, en sus desplazamientos artísticos y docentes, un hacer activo que se compromete socialmente. Un foco en este modelo ayudaría a promover subjetividades políticas, como la búsqueda de los lugares de resistencia y de empoderamiento de los/as artistas-docentes, en los distintos contextos y ámbitos de acción.

A partir de aquí, y a modo de colofón, preguntarnos por cómo dichas subjetividades contribuyen hacia el desarrollo social y cultural parece obvio, ya que al ser agentes/as de cambio se sitúan como posibilitadores/as de vida y cultura. Es desde aquí que se evidencian los cambios del campo artístico y de la educación artística en Chile, porque emerge la dimensión transformadora de las artes en educación, un nuevo hacer donde el profesorado se compromete no solo a enseñar técnicas, lenguajes artísticos o contenidos, sino sobre todo afectos, preguntas, problemas y sentidos de ser (García-Huidobro y Montenegro, 2020). Esto es, sin duda, lo que transforma a la cultura.

\section{Agradecimientos}

Proyecto financiado por el Concurso Interno de Investigación Científica y Tecnológica Regular 2018 de la Universidad de los Lagos, Chile (2018-2020).

\section{Referencias}

Acaso, M. y Megías, C. (2017). Art thinking. Cómo el arte puede transformar la educación. Paidós.

Aguirre, I. (2005). Teorías y prácticas en educación artística. Ensayo para una revisión pragmatista de la experiencia estética en educación. Octaedro.

Alcoff, L. y Potter, E. (1993). Feminist epistemologies. Routledge. 
Arévalo, A. y Hidalgo, F. (2015). Corporalidad docente: Un abordaje para aproximarse a la subjetividad del profesorado del sistema escolar chileno. Revista Corpografías: Estudios críticos de y desde los Cuerpos, 2(2), 162-179.

http://doi.org/10.14483/udistrital.jour.corpo.2015.1.a10

Atkinson, D. (2016). Without criteria: Art and learning and the adventure of pedagogy. International Journal of Art $\mathcal{E}^{2}$ Design Education, 36(2), 141-152. https://doi.org/10.1111/jade.12089

Balasch, M. y Montenegro, M. (2003). Una propuesta metodológica desde la epistemología de los conocimientos situados: Las producciones narrativas. Encuentros en Psicología Social, 1(3), 44-48.

Barad, K. (2003). Performatividad posthumanista: Hacia una comprensión de cómo la materia se convierte en materia. Signos: Revista de Mujeres en Cultura y Sociedad, 28(3), 801-831.

Barad, K. (2007). Meeting the universe halfway. Durke University Press. https://doi.org/10.1215/9780822388128

Blanco, N. (2006). Saber para vivir. En A. Piussi, y A. Mañeru (Eds.), Educación nombre común femenino (pp. 158-183). Octaedro.

Braidotti, R. (1991). Patterns of dissonance. A study of women in contemporary philosophy. Routledge.

Carbonell, J. (2001). La aventura de innovar. El cambio en la escuela. Morata.

Carrasco, S. y García-Huidobro, R. (2016). Educación artística. Construyendo desde la marginalidad y la precariedad. Revista Invisibilidades, 9, 105-112.

Carrasco, S. y Hernández, F. (2020). Cartografiar los afectos y los movimientos en el aprender corporeizado de los docentes. Movimento, 26, e26012. https://doi.org/10.22456/1982-8918.94792

Cobos, D. (2013). La educación artística en Chile: Aportes para una reflexión desde el análisis de algunas experiencias docentes. Revista Educarte, 44, 8-14.

Consejo Nacional de la Cultura y las Artes. (2012). Estudio para el levantamiento de buenas prácticas de educación artística en Chile. http://comunidadcreativalosrios.cultura.gob.cl/wpcontent/uploads/2018/01/informe-final-buenas-practicas-educacion-artistica.pdf

Consejo Nacional de la Cultura y las Artes. (2017). Política cultural. Los Lagos 2017-2022. https://issuu.com/consejodelacultura/docs/politica-los-lagos-2017-2022

Cornejo, R. (2008). Entre el sufrimiento individual y los sentidos colectivos: Salud laboral docente y condiciones de trabajo. Docencia, 35, 77-85.

Cornejo, R. (2009). Condiciones de trabajo y bienestar/malestar docente en profesores de enseñanza media de Santiago de Chile. Educación y Sociedad, 30(107), 409-426. https://doi.org/10.1590/S0101-73302009000200006

Dávila, J. (2018). La experiencia desde el cuestionamiento en colectivo. Algunas reflexiones desde el ICDAC sobre investigación artística. En N. Calderón y J. Ortiz (Coords.), Practicar la inestabilidad. Diálogos y acercamientos desde la investigación artística (pp. 113-141). Universidad Veracruzana.

Day, C. (2006). Pasión por enseñar: La identidad personal y profesional del docente y sus valores. Narcea.

Deleuze, G. (1995). Negotiations 1972-1990, trans. Martin Joughin. Columbia University Press.

De Pascual, A. y Lanau, D. (2018). El arte es una forma de hacer (no una cosa que se hace). Catarata. 
Ellsworth, E. (2005). Posiciones en la enseñanza: Diferencia, pedagogía y el poder de la direccionalidad. AKAL.

Errázuriz, L., Marini, G., Urrutia, I. y Chacón, R. (2014). Estudio diagnóstico del estado de la educación artística en la X Región de Los Lagos. Teatro del Lago y Pontificia Universidad Católica de Chile.

Fontdevilla, O. (2018). El arte de la mediación. Consomi.

Garcés, M. (2013). Un mundo común. Belaterra.

García-Huidobro, R. (2018). Hacia una formación onto-epistemológica de artistas-docentes. Un cruce de experiencias. En VVAA, Escenarios educativos latinoamericanos. Una mirada desde la universidad (pp. 20-31). Universidad Técnica de Manabí (UTM).

García-Huidobro, R. (2019). Experiencias del saber pedagógico de mujeres artistas-docentes. Narraciones biográficas sobre el desplazamiento del saber. Editorial Cuarto Propio.

García-Huidobro, R. y Ferrada, J. (2020). El compromiso cultural en las identidades del profesorado de artes en Chile. CUHSO, 3(2), 24-52.

http://doi.org/10.7770/2452-610x.cuhso.03.a02

García-Huidobro, R. y Montenegro, C. (2020). Las prácticas artísticas con enfoques feministas como experiencias educativas que promueven la transformación social. Revista Electrónica Educare, 24(1), 1-16. https://doi.org/10.15359/ree.24-1.23

García-Huidobro, R., Viveros, F. y Bahamonde, G. (2020). Creaciones y transformaciones en la onto-epistemología de los(as) artistas-docentes. Un proyecto al sur de Chile. Arte, individuo y sociedad, 32(3), 661-677. https://doi.org/10.5209/aris.64915

Gell, A. (1992). The technology of enchantment and the enchatment of technology. En J. Coote y A. Shelton (Eds.), Anthopology, art and aesthetics (pp. 40-60). Clarendon.

Gil, J. y Calderón, N. (2018). Arte, creación e investigación. Sobre el proceso creativo en el arte. En N. Calderón y J. Ortiz (Coord.), Practicar la inestabilidad. Diálogos y acercamientos desde la investigación artística (pp. 161-182). Universidad Veracruzana.

Goodson, I. (2004). Historias de vida del profesorado. Octaedro.

Guerra, L. (2017). De la inexistencia del arte. Brumaria.

Guzmán, M. (2015). Multiplicar los sujetos, encarnar los conocimientos: Plausibilidad de la epistemología social posmoderna de Donna Haraway. Boletín Científico Sapiens Research, 5(2), 39-44.

Hall, J. (2010). Making art, teaching art, learning art: Exploring the concept of the artist teacher. International Journal of Art \&ं Design Education, 29(2), 103-110. https://doi.org/10.1111/j.1476-8070.2010.01636

Haraway, D. (1997).Enlightment@science_wars.com: A personal reflection on love and war. Social Text, 50, 123-129. https://doi.org/10.2307/466820

Harding, S. (1987). Feminist and methodology. University Press.

Harding, S. (1993). Rethinking standpoint epistemology: What is strong objectivity? En L. Alcoff y E. Potter (Eds.), Feminist epistemologies (pp. 49-82). Routledge.

Hernández, F. (2009). ¿De qué hablan los artistas cuando realizan proyectos artísticospedagógicos? En R. Parramón (Coord.), Acciones irreversibles (pp. 299-309). EUMO. 
Jiménez, M. (2014). Los agentes sociales del contexto y su participación en la comunidad educativa. En M. Blanch (Coord.), Transformando la sociedad desde las aulas: Metodología de aprendizaje por proyectos para la innovación educativa en El Salvador (pp. 39-46). Narcea.

Kester, G. (2011). The one and other many. Contemporary collaborative art in a global context. Durke University Press. https://doi.org/10.1215/9780822394037

Llona, E. (2011). Estudio sobre el estado actual de la educación artística en la Región Metropolitana. IDIE.

Mercado, R. (1991). Los saberes docentes en el trabajo cotidiano de los maestros. Infancia $y$ Aprendizaje, (55), 59-72. https://doi.org/10.1080/02 103702.1991.10822305

Montenegro, C. (2019). Propuesta de didáctica feminista para la enseñanza escolar de las artes visuales: Pensar el espacio escolar de otra manera. Estudios Pedagógicos, 44(3), 289-302. https://doi.org/10.4067/SO718-07052018000300289

Mörsch, C. (2015). Contradecirse una misma. La educación en museos y exposiciones como práctica crítica. En A. Ceballos y A. Macaroff (Eds.), Contradecirse una misma. Museos y mediación educativa crítica. Experiencias y reflexiones desde las educadoras de la documenta 12 (pp. 10-21). Fundación Museos de la Ciudad.

Nardini, K. (2014). Volverse otro: El pensamiento encarnado y la «materia o importancia transformadora» de la teorización del (nuevo) materialismo feminista. Artnodes: Revista de Arte, Ciencia y Tecnología, 14, 18-25.

Ossa, C. (2017). Políticas y didácticas. Estudio sobre educación artística, creatividad social y ciudadanía en el CNCA. Universidad de Chile.

Raquimán, P. y Zamorano, M. (2017). Didáctica de las artes visuales. Una aproximación desde sus enfoques de enseñanza. Estudios Pedagógicos, 43(1), 439-456. https://dx.doi.org/10.4067/S07 18-07052017000100025

Ríos, M. (2018). De la formación en artes visuales a la práctica educativa: narrativas en torno a la constitución de identidades profesionales y tránsitos vividos por docentes nóveles (Tesis doctoral). Universidad de Barcelona.

Rivas, J. y Herrera, P. (2009). Voz y educación. La narrativa como interpretación de enfoque de la realidad. Octaedro.

Rogoff, I. (2011). El giro. Arte y Políticas de Identidad, 4, 253-266.

Sales, A., Traver Martí, J. y Moliner, O. (2019). Redefiniendo el territorio de la escuela: Espacios educativos y curriculum escolar para la transformación social. Revista Fuentes, 21(2), 177 188. https://doi.org/10.12795/revistafuentes.2019.v21.i2.03

Salgueiro, M. (1998). Saber docente y práctica cotidiana: Un estudio etnográfico. Octaedro.

Sancho, J. y Hernández, F. (Coord.). (2014). Maestros al vaivén. Aprender la profesión docente en el mundo actual. Octaedro.

Sofías. (2002). Escuela y educación. ¿Hacia dónde va la libertad femenina? Horas y Horas.

Tardif, M. (2004). Los saberes del docente y su desarrollo profesional. Narcea.

Theobald, N. (1990). An examination of the personal, professional, and school district characteristics on public school retention. Economics of Education Review, 9(3), 241-250. https://doi.org/10.1016/0272-7757(90)90005-P

Vezub, L. (2007). La formación y el desarrollo profesional docente frente a los nuevos desafíos de la escolaridad. Revista de Currículum y Formación del Profesorado, 11(1), 1-23. 
Viveros, F. (2020). Artistas y artistas-docentes en Chile: Orígenes, formación y desafíos. En R. García-Huidobro (Ed.), Cruzar la mirada. Resignificar a las artes en la sociedad actual (En edición). Ril Editores.

Wittrock, M. (1986). Handbook of research on teaching. Macmillan.

\section{Breve CV de las autoras}

\section{Rosario García-Huidobro}

Doctora en Artes y Educación por la Universidad de Barcelona. Su formación de pregrado es de Licenciada en Artes por la Pontificia Universidad Católica de Chile y Profesora de Educación Media por la Universidad Gabriela Mistral, en Santiago de Chile. Desarrolló los masters "Artes y Educación: un enfoque Construccionista” y "Estudios de la Diferencia Sexual", ambos en la Universidad de Barcelona. Se ha desempeñado como profesora de Artes en escuelas primarias y secundarias de Santiago. Ha trabajado como académica de la Universidad Católica Silva Henríquez y actualmente desarrolla docencia e investigación em la Universidad de los Lagos de Chile y se desempeña como Directora de Igualdad de Género de la Universidad. ORCID ID: https://orcid.org/O000-0002-1401-9437. Email: rosario.garcia-huidobro@ulagos.cl

\section{Ninoska Schenffeldt Ulloa}

Licenciada en Socióloga de la Universidad Católica de Temuco en Chile, actualmente se desempeña como profesional de apoyo en docencia e Investigación en la carrera de Pedagogía en Artes de la Universidad de Los Lagos. ORCID ID: https://orcid.org/0000o002-3454-45 11. Email: ninoska.schenffeldt@ulagos.cl 